\title{
Reducing morbidity in second stage cesarean section by Patwardhan's (shoulders first) method of delivery
}

\author{
Archana Kumari* \\ Department of Obstetrics and Gynecology, Rajendra Institute of Medical Sciences, Ranchi, Jharkhand, India \\ Received: 06 May 2018 \\ Accepted: 14 May 2018 \\ *Correspondence: \\ Dr. Archana Kumari, \\ E-mail: dr_karchana@yahoo.co.in \\ Copyright: (c) the author(s), publisher and licensee Medip Academy. This is an open-access article distributed under \\ the terms of the Creative Commons Attribution Non-Commercial License, which permits unrestricted non-commercial \\ use, distribution, and reproduction in any medium, provided the original work is properly cited.
}

\begin{abstract}
Background: To evaluate Patwardhan's method of delivering shoulders first during second stage cesarean section. Methods: 154 consecutive cases of cesarean section for second stage arrest or obstructed labor over a period of one year (July 2016 to June 2017) were included in the study. 77 cases delivered by Patwardhan's method comprised of study group and 70 cases delivered by vertex, 7 cases delivered by breech served as control. Fetal and maternal outcomes were compared in these two groups.

Results: Obstetric features like parity, maternal height, duration of pregnancy, hemoglobin levels, fetal weight were comparable in both groups. Perinatal outcomes were almost similar in both the groups. Extension of the uterine incision occurred in only 4 cases $(5.19 \%)$ in the study group compared to 16 cases $(20.77 \%)$ in control group. Excessive bleeding, uterine artery injury, need for blood transfusion and hysterectomy were also less in the study group.

Conclusions: Morbidity due to extension of uterine incision occurs commonly during second stage cesarean section, when hand is forcibly introduced in the pelvis to deliver impacted head, since lower uterine segment is edematous and fragile. Patwardhan's technique avoids this and hence should be practiced more widely. Its beauty lies in near absence of extension of uterine incision.
\end{abstract}

Keywords: Obstructed labor, Patwardhan method, Second stage cesarean section, Shoulder first

\section{INTRODUCTION}

Cesarean section in second stage of labor accounts for one fourth of all primary cesarean sections. ${ }^{1}$ Obstructed labor incidence per hundred live births ranges from $2.36 \%$ to $18.3 \%$ in developing countries where as in developed countries it is $1.6 \%$ to $3.9 \% .^{2}$ Incidence is more in developing countries as a result of unsupervised obstetric care at home and delayed referral. Cesarean section in second stage of labor for arrest or obstructed labor is always difficult because head is deeply impacted in the pelvis, liquor is drained out, lower uterine segment is stretched, tissues are often edematous and fragile. Maternal morbidity is enhanced due to increased chances of extension of uterine incision, injury to surrounding structures like bladder, hemorrhage, infection and need for hysterectomy. Neonatal morbidity is also increased.

\section{Methods of delivery of fetus}

Dexterity in extracting the fetus is an art and of utmost importance in reducing the maternal and neonatal morbidity. When head is deeply impacted in the pelvis, various methods of delivering the fetus could be;

Head low position, along with an upward pressure on the fetal shoulder by the operator.

While the operator's hand is inserted to lever out the head, pressure by an assistant on fetal shoulder is made. 
Sometimes, introducing the left hand below the head helps to lever out the head.

Push technique: Head is pushed upwards from the vagina by an assistant taking aseptic precaution and the operator gets hold of the head.

Pull technique: Useful in direct occipito-posterior position when the ventral aspect of the fetus is facing the incision. The leg is reached by introducing hand in upper segment of uterus and delivery is conducted as breech.

Patwardhan's technique: "Shoulders First" method: It is most useful when back of the fetus is anterior and the head is deeply impacted in the pelvis. The uterine incision is made at the level of shoulder. The anterior shoulder with the arm is delivered first by hooking a finger in the elbow if required. Posterior shoulder is then rotated forwards and similarly delivered along with the other arm. ${ }^{3}$ Thorax of the fetus is then gripped with fingers of hands on both axilla. Trunk, breech and lower limbs are successively delivered by gentle traction coupled with fundal pressure by the anesthetist or the assistant. Finally, the head is delivered by lifting the trunk upwards. This technique avoids introducing hands into fragile and edematous lower uterine segment, thus chances of extension of uterine incision and injury to surrounding structures is low.

Modified Patwardhan's technique: Useful in occipito transeverse position. One arm, leg of the same side, both buttocks, opposite leg, trunk, opposite arm and finally head is taken out in succession.

Patwardhan's technique despite potential advantages, is one of the least explored methods of delivery of impacted head in second stage cesarean sections. So, this study was conducted to analyse and compare the Patwardhan's technique with conventional methods of delivery in second stage cesarean sections in terms of feto-maternal morbidity.

\section{METHODS}

This is an observational study over a period of one year from July 2016 to June 2017 in Rajendra Institute of Medical Sciences, a tertiary care teaching hospital and referral centre for Jharkhand state. 154 successive cases of cesarean section done for 2nd stage arrest or obstructed labor with impacted head were included in the study.

We did not include transverse lie, breech or other causes of obstructed labor in present study. Cases of previous cesarean undergoing VBAC were also excluded from study. 77 cases delivered by Patwardhan's (shoulders first) technique comprised of study group. 77 cases (70 cases delivered by vertex and 7 cases by breech) served as control group. All cases were given pre-operative intravenous fluids and antibiotics. Standard anesthesia was spinal. Obstetric outcomes like extension of uterine incision, injury to surrounding structures like bladder, excessive bleeding, need for hysterectomy and need for blood transfusions was noted in both groups. Neonatal features like birth weight, asphyxia, NICU admission and stillbirth were also compared in two groups.

\section{RESULTS}

During study period, total deliveries were 7017 out of which 3014 (43.45\%) were LSCS. 154 (5\%) were second stage cesarean with impacted head (excluding causes like transverse lie, arrested breech, hydrocephalus and other causes of obstructed labor).

Table 1 shows that obstetric features like parity, period of gestation, pre-operative hemoglobin levels were comparable in both the groups.

Table 1: Obstetric features.

\begin{tabular}{|lll|}
\hline Parity & $\begin{array}{l}\text { Study Group } \\
n=77\end{array}$ & $\begin{array}{l}\text { Control Group } \\
n=77\end{array}$ \\
\hline Primi & $26(33.7 \%)$ & $22(28.5 \%)$ \\
\hline Multi & $40(52 \%)$ & $45(58.4 \%)$ \\
\hline Grand Multi & $11(14.2 \%)$ & $10(12.9 \%)$ \\
\hline Pregnancy & & \\
\hline$<37$ weeks & $7(9 \%)$ & $10(12.9 \%)$ \\
\hline 37-40weeks & $63(82 \%)$ & $58(75.3 \%)$ \\
\hline$>40$ weeks & $7(9 \%)$ & $9(11.6 \%)$ \\
\hline Pre-op Hemoglobin & & \\
\hline$>10$ gm & $8(10.3 \%)$ & $10(12.9 \%)$ \\
\hline $8-10$ & $43(55.8 \%)$ & $46(60 \%)$ \\
\hline $6-8$ & $20(26 \%)$ & $16(20.7 \%)$ \\
\hline$<6$ & $6(7.7 \%)$ & $5(6.4 \%)$ \\
\hline
\end{tabular}

Table 2 shows that neonatal outcomes like fetal weight, degree of asphyxia, NICU admission and stillbirth in the study (Patwardhan's group) and control group were almost similar.

Table 2: Neonatal Outcome

\begin{tabular}{|lll|}
\hline $\begin{array}{l}\text { Fetal wt. } \\
\text { (kg) }\end{array}$ & $\begin{array}{l}\text { Study Group } \\
n=77\end{array}$ & \\
\hline $2.5-3.0$ & $10(12.98 \%)$ & $12(15.58 \%)$ \\
\hline $3.0-3.5$ & $49(63.63 \%)$ & $51(66.23 \%)$ \\
\hline$>3.5$ & $18(23.37 \%)$ & $14(18.18 \%)$ \\
\hline Asphyxia & & \\
\hline Nil & $51(66.23 \%)$ & $49(63.63 \%)$ \\
\hline Mild/Mod. & $10(12.98 \%)$ & $11(14.28 \%)$ \\
\hline Severe & $7(9.09 \%)$ & $8(10.38 \%)$ \\
\hline Still birth & $9(11.68 \%)$ & $9(11.68 \%)$ \\
\hline
\end{tabular}

Birth weight ranged between $2.5 \mathrm{~kg}$ to $3.9 \mathrm{~kg}$. This means that any intra-operative complications were not related to 
birth weight. Birth asphyxia and still birth rate were not related to the technique of delivery.

Figure 1 (flow chart) shows the condition of lower uterine segment and extension of uterine incision in two groups. Transverse extension occurred in 3 cases $(3.89 \%)$ in Patwardhan's group compared to 11 cases $(14.28 \%)$ in control group.

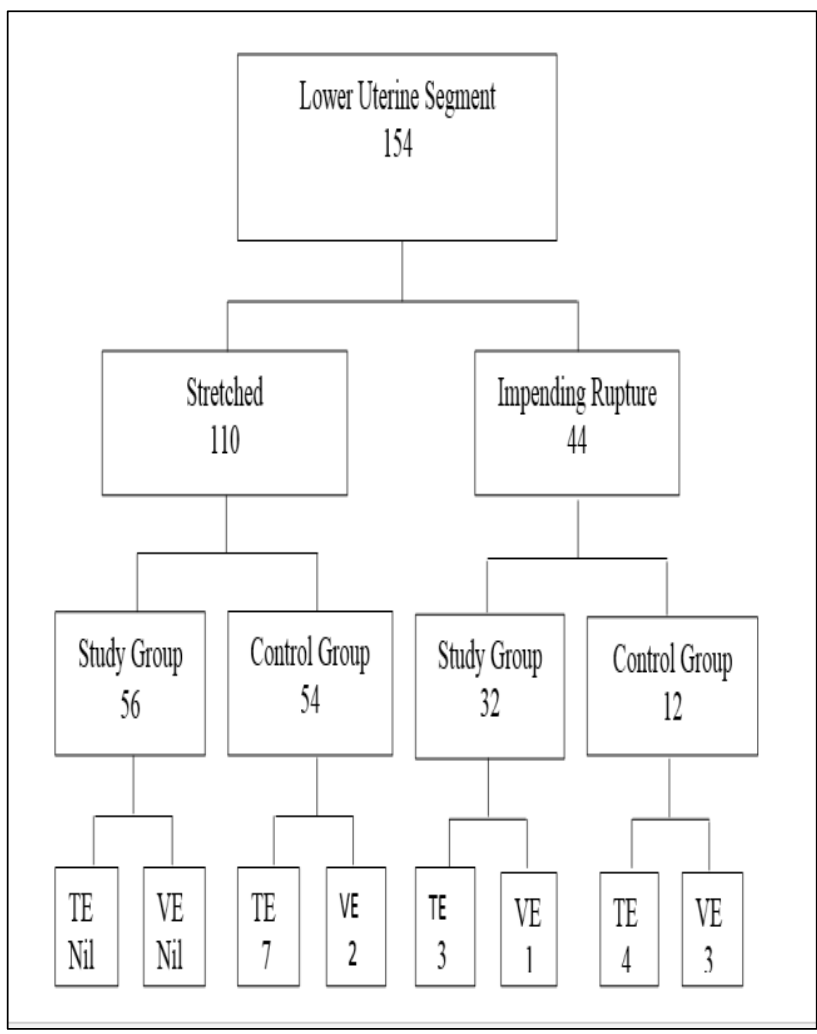

Figure 1: Intra-operative features.

Vertical extension occurred in 1 case $(1.29 \%)$ only in study group whereas 5 cases $(6.49 \%)$ in control group.Total number of uterine incision extension was 4 $(5.19 \%)$ in study group versus $16(20.77 \%)$ in control group.

Table 3: Intraoperative Morbidities.

\begin{tabular}{|c|c|c|}
\hline & $\begin{array}{l}\text { Study Group } \\
\mathrm{n}=77\end{array}$ & $\begin{array}{l}\text { Control Group } \\
\mathrm{n}=77\end{array}$ \\
\hline $\begin{array}{l}\text { Uterine artery } \\
\text { injury }\end{array}$ & Nil & $8(10.38 \%)$ \\
\hline Bladder injury & Nil & Nil \\
\hline $\begin{array}{l}\text { Broad ligament } \\
\text { hematoma }\end{array}$ & Nil & $2(2.59 \%)$ \\
\hline \multicolumn{3}{|l|}{$\mathrm{PPH}$} \\
\hline Traumatic & $2(2.59 \%)$ & $14(18.18 \%)$ \\
\hline Atonic & $3(3.89 \%)$ & $5(6.49 \%)$ \\
\hline Blood transfusion & $11(14.28 \%)$ & $30(38.96 \%)$ \\
\hline Hysterectomy & $1(1.29 \%)$ & $3(3.89 \%)$ \\
\hline $\begin{array}{l}\text { Fracture shaft of } \\
\text { humerus }\end{array}$ & $1(1.29 \%)$ & Nil \\
\hline
\end{tabular}

Table 3 shows 8 cases $(10.38 \%)$ in control group had uterine artery injury which required uterine artery ligation, while none in study group. Two cases in the control group had broad ligament hematoma, while none in study group. Intra-operative traumatic PPH was more in control group, 14 cases $(18.18 \%)$ versus only 2 cases $(2.59 \%)$ in study group. 30 cases $(38.9 \%)$ required blood transfusion of 2-4 units in control group compared to only 11 cases $(14.28 \%)$ in study group.

Three cases in control group required hysterectomy due to extensive extension of uterine incision and/or PPH. One case in study group required hysterectomy for uncontrolled atonic PPH. One case of fracture humerus was seen in the study group. There were no maternal deaths or bladder injury in the present series.

\section{DISCUSSION}

Second stage arrest or obstructed labor demands immediate cesarean section when vaginal delivery is not possible. These women are in prolonged labor and dehydrated and therefore, require adequate hydration, and also antibiotics to prevent infection. Ideally, an experienced obstetrician should undertake this difficult condition, be prepared to manage complications especially extension of uterine incision and hemorrhage. Most of the cesarean, in present series were done by senior residents on duty.

Extracting the fetus is an art, which can make lots of difference to maternal and fetal morbidity. In the present study, the control group and the study group were comparable in terms of obstetric features like parity, period of gestation and pre-operative hemoglobin. This is important to draw any conclusion on the safety of Patwardhan's technique.

In the present study, there is significantly low incidence of extension of uterine incision, $4(5.19 \%)$ in the study group versus $(20.77 \%)$ in control group and consequently, traumatic PPH and need of blood transfusion was also less. Blood transfusions in the study group were reported mainly for treatment of anemia and not for intra-operative complications.

Similar observations have been reported in other studies. $^{4-8}$ Desai $\mathrm{P}$ et al reported extension of uterine incision in only $1 / 80(1.25 \%)$ in Patwardhan's technique compared with 28/44 (63.9\%) when the method was not used. ${ }^{4}$ Mukhopadhyay $\mathrm{P}$ et al reported uterine incision extension in only 6 out of 50 cases in Patwardhan's group ( 3 transverse, 3 vertical) versus 27 out of 50 cases (18 transverse, 9 vertical) in control group delivered by conventional 'push' technique..$^{5}$ Sarkar D et al reported transverse extension of uterine incision in 7/74 cases $(9.45 \%)$ in Patwardhan's technique compared to $19 / 74$ cases $(25.67 \%)$ in conventional technique. Vertical extension was seen only in 1 case in Patwardhan's technique compared to 13 cases in other techniques. ${ }^{6}$ 
Saha PK et al in their series of 79 cases, reported no incidence of uterine incision extension in 35 deliveries by Patwardhan's technique whereas10/44 cases (22.7\%) delivered by head or breech had uterine incision extension. ${ }^{7}$ Bansiwal $\mathrm{R}$ et al also reported significantly less uterine incision extension in Patwardhan's group $(3.1 \% \text { versus } 23.9 \%,)^{8}$

Attempt to forcibly introduce hand in the pelvis to deliver impacted or jammed head causes uncontrolled injury to the fragile and edematous lower uterine segment as well as surrounding tissues like bladder.

Of course, the extension is often realized after the baby is delivered. Patwardhan's shoulder first technique avoids entry of hand into pelvis and hence significantly reduces morbidity like uterine extension, uterine artery injury, traumatic PPH and also need for blood transfusions. Prevention of uterine incision extension is also important for future aspects of delivery if trial of VBAC is to be given. Extension of incision is a contraindication to allowing subsequent vaginal delivery..$^{9,10}$

There was no significant difference of fetal outcome by the two delivery methods in the present study. Desai P et al reported significantly low incidence of fetal asphyxia in babies delivered by Patwardhan's method and concluded that there might have been the contribution of smoothness in baby delivery without major trauma to it. 4 Other studies have reported no differences in fetal outcome similar to present study. ${ }^{5,6}$ One case of fracture shaft of femur in the present study, also reported in other studies was preventable, had the pull been applied on the joints and not on the shaft of bone., ${ }^{4,7}$

Although the present study had no incidence of bladder injury, 2 cases of bladder injury in the control(nonPatwardhan's) group have been reported in studies of Desai $P$ et al and Mukhopadhyay et al. ${ }^{4,5}$ Study of Sethuram R has stressed on the requirement of adequate training for delivery of deeply engaged head. ${ }^{11}$ This study also agrees with the view that inpatient training in shoulders first (Patwardhan's) method of delivery of the obstetricians in periphery is required to reduce maternal morbidity.

\section{CONCLUSION}

Morbidity due to extension of uterine incision occurs commonly during LSCS in the second stage for arrest or obstructed labour, when hand is forcibly introduced into the pelvis to deliver the impacted head since lower uterine segment is stretched out, edematous and fragile. Patwardhan's method is a unique method to deliver baby without introducing hand into the pelvis through the lower uterine segment.

Maternal morbidity like uterine incision extension, uterine artery injury, need for blood transfusion and traumatic PPH by using Patwardhan's method, is therefore considerably reduced. Hence, Patwardhan's method should be practiced widely. More obstetricians at periphery, residents in medical college, should be trained in this obstetric skill to reduce maternal morbidity.

Funding: No funding sources

Conflict of interest: None declared

Ethical approval: The study was approved by the Institutional Ethics Committee

\section{REFERENCES}

1. Evaluation of caesarean delivery. The American College of Obstetricians and Gynaecologists Women's Health Care Physicians, 409, SW.PO Box 96920.Washington, DC. 20090-6920. ACOG; 2000

2. Maternal Mortality update- UNFPA assistance of maternal mortality prevention activities: an overview 1998-99

3. Patwardhan BD, Motashaw ND. Caesarean Section. J Obstet Gynecol India.1957;8:1-15.

4. Desai P, Desai P, Shah A, Shah N. Preventing complications by 'shoulders first' method of delivery in cases of obstructed labor. J Obstet Gynecol India. 2001;51:91-4

5. Mukhopadhyay P, Naskar T, Dalui R, Hazra S, Bhattacharya D. Evaluation of Patwardhan's technic- a four year study in a rural teaching hospital. J Obstet Gynecol India. 2005;55:244-6

6. Sarkar D, Mandal D, Duttaray C, Parmanik S, Saha PK, Sengupta SK. Patwardhan's technique in obstructed labor- Still an alive obstetric art. Indian J Perinatol Reprod Biol. 2015;5:16-8

7. Saha PK, Gulati R, Goel P, Tandon R, Huria A. Second stage caesarean section: Evaluation of Patwardhan's technique. J Clin Diagn Res. 2014;8:93-5

8. Bansiwal R, Anand HP, Jindal M. Safety of Patwardhan technique in deeply engaged head. Int $\mathbf{J}$ Reprod Contracept Obstet Gynecol.2016;5:1562-5

9. Mahapatra M. Patwardhan's technique: it's impact on maternal and fetal outcome. YUVA J Med Sci. 2015;1:26-7.

10. Murphy DJ, Leibling RE, Verity L, Swingler R, Patel R. Early maternal and neonatal morbidity associated with operative delivery in second stage of labor: a cohort study. Lancet. 2001;358:1203-7.

11. Sethuram R, Jamjute R, Kevelighan E. Delivery of deeply engaged head: a lacuna in training. J Obstet Gynecol India. 2010;30:545-9.

Cite this article as: Kumari A. Reducing morbidity in second stage cesarean section by Patwardhan's (shoulders first) method of delivery. Int J Reprod Contracept Obstet Gynecol 2018;7:2208-11. 